\title{
An Efficient Flow Shop Scheduling Problem With Makespan Objective
}

\author{
S. Jayasankari ${ }^{1}$ Dr. S. Jayakumar ${ }^{2} \&$ Dr. R. Vijayaragavan ${ }^{3}$ \\ ${ }^{1}$ Research Scholar, PG and Department of Mathematics, AAGA College, Cheyyar 604 407, Tamil Nadu, India. \\ ${ }^{2}$ Head of the Department, PG and Department of Mathematics, AAGA College, Cheyyar 604 407, Tamil Nadu, \\ India.
}

${ }^{3}$ Associate Professor, Department of Mathematics, Thiruvalluvar University, Vellore, Tamil Nadu, India.

Article History: Received:11 January 2021; Accepted: 27 February 2021; Published online: 5 April 2021

\begin{abstract}
Scheduling ' $\mathrm{n}$ ' job in ' $\mathrm{m}$ ' machine is a tedious task for the Research scholar to solve this type of problem. Flow shop scheduling has its origin in the manufacturing industries in the early 1954. In this paper, we have developed an algorithm with the objective is to minimize the total elapsed time (makespan). Examples are illustrated to demonstrate the proposed approach in detail. Finally, the result obtained under the proposed method is compared with the existing methods available in the literature. It is found that our algorithm performs better than the existing algorithm and the result have been incorporated in this article.
\end{abstract}

KEYWORDS: Flow shop, Heuristic, Permutation, Makespan.

\section{INTRODUCTION:}

Scheduling is the process of arranging, controlling and optimizing work and workload in a manufacturing process. Flow shop scheduling is a special case of job shop scheduling where there is a strict order of all operations to be performed on all jobs. Even though flow shop scheduling has its origin in manufacturing industries. It has been widely used in the service sector. Johnson was the first investigator in this area of research. The study of scheduling criteria made by convey et.al. (1960), Gere(1962), Oyetungi (2009) are all very interesting in their findings. In particular, Oyetungi(2009) not less than 29 different scheduling criteria have been identified. The total elapsed time is directly proportional to the production cost. It is also an important scheduling criteria according to Oluleye(1999) and Shahzad(2010).

In this article, we have been focusing on minimizing the total elapsed time. It is very important when compared with the other objective. The selection of order in which the jobs are going to be processed (sequenced) is called sequencing problem. This is in order to make effective utilization of available resources. This type of problem as restriction upon availability of resources either man made or machine made. The problem of finding a sequence among the $(n !)^{\mathrm{m}}$ sequences for processing the jobs which gives minimum makespan.

\section{LITERATURE REVIEW:}

Manufacturing problem as its origin in flow shop scheduling in the early 1954. Flow shop scheduling was introduced by Johnson with the objective of minimizing the makespan(total elapsed time). Later on, so many researchers found different heuristic algorithm for minimization of makespan in the flow shop scheduling problems.

In the year 1965, Palmer gave a heuristic algorithm. It can be applied to the large-sized problems by giving priority to the jobs and it is known as palmer's slope index method.

Later in the year 1970, Cambel, Deduk and Smith extended Johnson's algorithm for m machine flow shop scheduling problem with the objective of minimizing makespan. They called it has CDS method. In the year 1971, Gupta solved this problem in a different way.

Later on, during 1983, Nawaz, Enscore and Ham gave the priority rule in which a job with maximum total processing time in all the machine should be given higher priority than the job with minimum total processing time. Based on this, they developed a heuristic algorithm and it is known as NEH heuristic.

In the year 2013, Nagamalleswara Rao et.al. presented a time deviation technique using a heuristic approach to minimize the makespan (Total Elapsed Time).

Later on, during the year 2016, Jayakumar, Shanthi and Meganathan used a heuristic approach to solve PFSSP. They also consider the same $\mathrm{n}$ job $\mathrm{m}$ machine case and compared their algorithm with the existing 
algorithm in the literature. They concluded that their algorithm is superior than the existing algorithm found in the literature.

\begin{tabular}{|c|c|c|c|c|c|}
\hline $7^{J} \mathrm{Job}$ & 1 & 2 & 3 & $\cdots$ & $\mathrm{N}$ \\
\hline $\mathrm{M}_{1}$ & $\mathrm{t}_{11}$ & $t_{12}$ & $\mathrm{t}_{13}$ & $\ldots$ & $\mathrm{t}_{1 \mathrm{n}}$ \\
\hline $\mathrm{M}_{2}$ & $\mathrm{t}_{21}$ & $\mathrm{t}_{22}$ & $\mathrm{t}_{23}$ & $\ldots$ & $\mathrm{t}_{2 \mathrm{n}}$ \\
\hline $\mathrm{M}_{3}$ & $\mathrm{t}_{31}$ & $t_{32}$ & $\mathrm{t}_{33}$ & $\ldots$ & $\mathrm{t}_{3 \mathrm{n}}$ \\
\hline . & . & . & . & . & . \\
\hline . & $\cdot$ & . & $\cdot$ & $\cdot$ & . \\
\hline$\cdot$ & . & . & . & $\cdot$ & $\cdot$ \\
\hline $\mathrm{M}_{\mathrm{m}}$ & $\mathrm{t}_{\mathrm{m} 1}$ & $\mathrm{t}_{\mathrm{m} 2}$ & $\mathrm{t}_{\mathrm{m} 3}$ & $\ldots$ & $\mathrm{t}_{\mathrm{mn}}$ \\
\hline
\end{tabular}

In the same year 2016, Jayakumar, Meganathan and Shanthi solved the shop floor scheduling problem with two machine $\mathrm{n}$ job problem by using a heuristic approach in the result have been compared with Johnson method and it was found that their algorithm is superior than Johnson's algorithm.

Later in the year 2019, Jayakumar and Vasudevan developed an algorithm for permutation flow shop scheduling problem with objective of minimizing the makespan. The new modified algorithm gives the feasible solution and they concluded that their algorithm not only minimizing the makespan but also it reduces the resource idle time.

\section{JJV ALGORITHM:}

Step 3.1: List the jobs along with their processing times on each machine in a table.

Step 3.2: Examine the processing times on machines $M_{1}, M_{2}, M_{3}, \ldots, M_{n}$ in each column in the table and find the maximumprocessing time and subtract all the other processing time from it. Now we get at least one of the processing time is zero.

Step 3.3: If the processing time 'zero' in the first machine then form the group $X=\{\}$ and put the corresponding job in the group $X$. Suppose if it is on the last half of the machines, form the group $Y=\{\}$ and put the corresponding job in the group Y and go to step 3.4. Suppose if it is not on the first or last machine, cross off that corresponding machine operation time row without making any changes and go to step 3.2.

Step 3.4: Now cancel the corresponding job with respect to the zero-processing time. Then form the reduced matrix with the left-out processing time. Then repeat the above steps and put all the jobs in the corresponding group.

Step 3.5: Now we get the groups $X$ and $Y$. Now reverse the jobs in the groups $X$ and $Y$ and put the jobs in the group $\mathrm{Y}$ first in the sequence and then put the jobs in the group $\mathrm{X}$ last in the sequence.

Step 3.6: Using the obtained sequence, calculate the total elapsed time.

\section{NUMERICAL EXAMPLE}

Sequencing of $\mathrm{N}$ jobs in $\mathrm{M}$ machines can be given by the following problem 
Table 4.1

\begin{tabular}{|c|c|c|c|c|c|}
\hline $\mathrm{M}_{1}$ & $\mathrm{~J}_{1}$ & $\mathrm{~J}_{2}$ & $\mathrm{~J}_{3}$ & $\mathrm{~J}_{4}$ & $\mathrm{~J}_{5}$ \\
\hline $\mathrm{M}_{2}$ & 6 & 8 & 10 & 7 & 9 \\
\hline $\mathrm{M}_{3}$ & 4 & 3 & 5 & 7 & 3 \\
\hline $\mathrm{M}_{4}$ & 8 & 7 & 11 & 9 & 6 \\
\hline
\end{tabular}

Choose the maximum processing time in the given table. In the above table, the maximum processing time is 11. So, subtract all the other processing time from 11 and form the new table.

Table 4.2

\begin{tabular}{|c|c|c|c|c|c|}
\hline Job & $\mathrm{J}_{1}$ & $\mathrm{~J}_{2}$ & $J_{3}$ & $\mathrm{~J}_{4}$ & $\mathrm{~J}_{5}$ \\
\hline $\mathrm{M}_{1}$ & 5 & 3 & 1 & 4 & 2 \\
\hline $\mathrm{M}_{2}$ & 6 & 7 & 8 & 7 & 6 \\
\hline $\mathrm{M}_{3}$ & 7 & 8 & $\phi$ & 4 & 8 \\
\hline $\mathrm{M}_{4}$ & 3 & 4 & 0 & 2 & 5 \\
\hline
\end{tabular}

Here we get zero in the third job. It is on the last machine. So, we form the group $\mathrm{Y}$ and put the job $\mathrm{J}_{3}$ in that group $Y$. i.e.) $\mathrm{Y}=\left\{\mathrm{J}_{3}\right\}$.

Now cross off the third job and form the reduced table with the left-out processing time.

Here in the left-out processing time, the maximum processing time is 8 . So, subtract all the entries in the table from 8 and form the new table.

Table 4.3

\begin{tabular}{|c|c|c|c|c|}
\hline Machine & $\mathrm{J}_{1}$ & $\mathrm{~J}_{2}$ & $\mathrm{~J}_{4}$ & $\mathrm{~J}_{5}$ \\
\hline $\mathrm{M}_{1}$ & 3 & 5 & 4 & 6 \\
\hline $\mathrm{M}_{2}$ & 2 & 1 & 1 & 2 \\
\hline $\mathrm{M}_{3}$ & 1 & 0 & 4 & 0 \\
\hline $\mathrm{M}_{4}$ & 5 & 4 & 6 & 3 \\
\hline
\end{tabular}

Here we get zero in the third machine. Hence cancel the third machine and form the new table with the left-out processing time.

In the left-out processing time, the maximum processing time is 6 . So, subtract all the entries in the table from 6 and form the new table. 
Table 4.4

\begin{tabular}{|c|c|c|c|c|}
\hline Machine Job & $\mathrm{J}_{1}$ & $\mathrm{~J}_{2}$ & $\mathrm{~J}_{4}$ & $\mathrm{~J}$ \\
\hline $\mathrm{M}_{1}$ & 3 & 1 & 2 & 0 \\
\hline $\mathrm{M}_{2}$ & 4 & 5 & 5 & 4 \\
\hline $\mathrm{M}_{4}$ & 1 & 2 & $\phi$ & 3 \\
\hline
\end{tabular}

Here we get zero in the fourth job in the last machine and fifth job in the last machine. So put the job $\mathrm{J}_{4}$ in the group $\mathrm{Y}$ and put the job $\mathrm{J}_{5}$ in the group $\mathrm{X}$. Therefore, $\mathrm{X}=\left\{\mathrm{J}_{5}\right\}$ and $\mathrm{Y}=\left\{\mathrm{J}_{3}, \mathrm{~J}_{4}\right\}$.

In the reduced table, the maximumprocessing time is 5 . So subtract all the entries from 5.

Table 4.5

\begin{tabular}{|c|c|c|}
\hline Machine & $\mathrm{J}_{1}$ & $\mathrm{~J}_{2}$ \\
\hline $\mathrm{M}_{1}$ & 2 & 4 \\
\hline $\mathrm{M}_{2}$ & 1 & 0 \\
\hline $\mathrm{M}_{4}$ & 4 & 3 \\
\hline
\end{tabular}

Here we get zero in the second machine. So cross off the second machine and form the new table. In the left-out processing time, the maximum processing time is 4 and subtract all the entries from 4 .

Table 4.6

\begin{tabular}{|c|c|c|}
\hline Machine Job & $\mathrm{J}_{1}$ & $\mathrm{~J}_{2}$ \\
\hline $\mathrm{M}_{1}$ & 2 & 0 \\
\hline $\mathrm{M}_{4}$ & 0 & 1 \\
\hline
\end{tabular}

Here we get zero in the first job in the last machine and second job in the first machine. So put the job $\mathrm{J}_{1}$ in the group $Y$ and put the job $J_{2}$ in the group $X$. Therefore, $X=\left\{J_{5}, J_{2}\right\}$ and $Y=\left\{J_{3}, J_{4}, J_{1}\right\}$.

Now reverse the order in the groups $X$ and $Y$. i.e.) $X=\left\{J_{2}, J_{5}\right\}$ and $Y=\left\{J_{1}, J_{4}, J_{3}\right\}$ and put the jobs in the group $Y$ first in the sequence and then put the jobs in the group $\mathrm{X}$ last in the sequence.

\begin{tabular}{|l|l|l|l|l|}
\hline $\mathrm{J}_{1}$ & $\mathrm{~J}_{4}$ & $\mathrm{~J}_{3}$ & $\mathrm{~J}_{2}$ & $\mathrm{~J}_{5}$ \\
\hline
\end{tabular}

Now calculate the total elapsed time

\begin{tabular}{|c|c|c|c|c|c|c|c|c|}
\hline \multirow{2}{*}{ Job } & \multicolumn{2}{|c|}{$\mathrm{M}_{1}$} & \multicolumn{2}{|c|}{$\mathrm{M}_{2}$} & \multicolumn{2}{c|}{$\mathrm{M}_{3}$} & \multicolumn{2}{c|}{$\mathrm{M}_{4}$} \\
\cline { 2 - 9 } & In & Out & In & Out & In & Out & In & Out \\
\hline $\mathrm{J}_{1}$ & 0 & $0+6=6$ & 6 & $6+5=11$ & 11 & $11+4=15$ & 15 & $15+8=23$ \\
\hline $\mathrm{J}_{4}$ & 6 & $6+7=13$ & 13 & $13+4=17$ & 17 & $17+7=24$ & 24 & $24+9=33$ \\
\hline $\mathrm{J}_{3}$ & 13 & $13+10=23$ & 23 & $23+3=26$ & 26 & $26+5=31$ & 33 & $33+11=44$ \\
\hline
\end{tabular}




\begin{tabular}{|l|l|l|l|l|l|l|l|l|}
\hline $\mathrm{J}_{2}$ & 23 & $23+8=31$ & 31 & $31+4=35$ & 35 & $35+3=38$ & 44 & $44+7=51$ \\
\hline $\mathrm{J}_{5}$ & 31 & $31+9=40$ & 40 & $40+5=45$ & 45 & $45+3=48$ & 51 & $51+6=57$ \\
\hline
\end{tabular}

\section{RESULT:}

Table 5.1

\begin{tabular}{|c|c|c|}
\hline No. of Observation & Technique & Total elapsed time \\
\hline 1. & JJV algorithm & 57 \\
\hline 2. & Palmer method & 59 \\
\hline 3. & CDS method & 57 \\
\hline 4. & NEH method & 57 \\
\hline 5. & JV algorithm & 59 \\
\hline 6. & $\begin{array}{c}\text { Gupta's algorithm } \\
\text { algorithm }\end{array}$ & 63 \\
\hline 7. & $\begin{array}{c}\text { Nagamalleswara Rao et.al. } \\
\end{array}$ & \\
\hline
\end{tabular}

\section{CONCLUSION:}

In this paper a systematic procedure is developed to obtain the minimum total elapsed time. Based on the result obtained indicates that JJV algorithm performs better than Palmer, Gupta, JV and Nagamalleswara Rao et.al. algorithms. The proposed algorithm gives near the optimal solution, rather than the optimal one. We conclude that our algorithm is superfast in solvingthe flow shop scheduling problem when compared with CDS and NEH algorithm.

\section{REFERENCES:}

1. Campell H G, Dudek R.A. and Smith M.L., "A heuristic algorithm for n-jobsm-machines sequencing problems", Management Science, Vol. 16B, (1970), pp.166-177.

2. Conway R.W., Maxwell W.L. and Miller L.W., "Theory of scheduling", Dover Publications INC, 1967.

3. Gere W.S., "A heuristic approach to job shop scheduling",Ph.D. Thesis, Carnegie Institute of Technology (1962).

4. Jayakumar Sundaramoorthy, Sathiya Shanthi Ramesh Babu and Meganathan Rangaraji, "An Heuristic Approach for Solving Permutation Flow Shop Scheduling Problem", International Journal of Emerging Technology and Advanced Engineering, 6(4), (2016), pp. 144-146.

5. Jayakumar and Vasudevan, "Heuristic algorithm for permutation flow shop scheduling", International Journal of Technology, 9(1), (2019), pp.5-7.

6. Nagamalleswara Rao, O. Naga Raju and Ramesh Babu I., "Modified Heuristic time deviation technique for job sequencing and computation of minimum total elapsed time", International Journal of Computer Science and Information Technology(IJCSIT), 5(3), (2013), pp.67-77.

7. Nawaz M, Enscore Jr.E. and Ham I, "A Heuristic Algorithm for the m-Machine, n-Job Flow-Shop Sequencing Problems", OMEGA, The International Journal of Management Science 11, no.1, (2009), pp. $1-10$. 
8. Oluleye, A.E., Oyetunji, E.O., "Performance of some static flow shop scheduling heuristic", Directions in Mathematics, (1999), pp. 315-327.

9. Oyetunji, E.O. "Some common performance measure in scheduling problems', Research Journal of Applied Sciences, Engineering and Technology, 1(2), (1999), pp. 6-9.

10. Palmer D S "Sequencing jobs through a multi stage process in the minimum total time - A quick method for obtaining a near optimum", Operations Research, 16 (1956), pp. 101-107. 